\title{
The physician's role in the prevention of AIDS
}

\author{
LEONARD H. CALABRESE, DO \\ DENNIS KELLEY, BA, RN
}

Primary care physicians possess the unique opportunity to halt the biobehavioral spread of AIDS through appropriate preventive education and behavioral modification techniques. This review presents a comprehensive framework dealing with HIV transmission, specific strategies for prevention, issues surrounding antibody testing and counseling, as well as information useful in overcoming obstacles for preventive educational programs. The information is drawn from both a review of the literature as well as current clinical guidelines.

The AIDS epidemic will be with us for the rest of our professional lives, and it is critically important that all physicians become involved in the fight against it. To meet the challenge of AIDS, physicians will need to be not only well versed in the diagnosis and management of human immunodeficiency virus (HIV) infection and related diseases, but they also must be active in AIDS education and prevention.

The reason for this urgency is that despite remarkable progress, such as identification of the etiologic agent, diagnostic test development, and advances in the management of AIDS patients, there still is no effective treatment or vaccine--and not a single patient has been cured. Furthermore, AIDS remains an almost totally preventable disease, because it basically is transmitted by willful behavior (sexual activity and drug usage), and it is, therefore, theoretically possible to halt the spread by appropriate education and behavioral modification.

The physician is in an ideal position to become actively involved in AIDS education and prevention, because virtually all persons come under medi- cal care at some time, and the physician/patient relationship is not restricted by the social standards that impede the use of mass communication or the schools to educate the population.

This review provides a framework for overcoming the obstacles that might confront the physician, particularly the primary care physician, who wishes to become active in this educational process.

\section{HIV transmission}

Although the topic of transmission has been reviewed thoroughly in other parts of this series, it is important to highlight aspects of what is known relevant to preventive strategies. It appears that $\mathrm{HIV}$ is transmitted in three ways: intimate sexual contact, via blood-borne routes, and perinatally from the infected mother to the newborn.

Sexual transmission accounts for nearly $80 \%$ of reported cases. A growing body of data demonstrates that HIV can be transmitted from man to man, man to woman, woman to man, and, rarely, woman to woman. ${ }^{1}$ The relative risk of transmission from different types of sexual acts has been difficult to define, but numerous studies of male homosexuals have indicated that anal-receptive intercourse is the highest risk sexual practice.

Oral sex (fellatio) has been more difficult to incriminate as an effective route to transmission, but it was a significant factor in at least one study, ${ }^{2}$ and it has been strongly suspected in several HIVinfected patients who were never inseminated anally (LH Calabrese, unpublished data). Intimate kissing (French kissing) has not been documented statistically as high-risk sexual behavior, but because HIV has been (rarely) isolated from saliva and with the potential for microscopic bleeding in the mouth as well as mouth ulcers, it is important to recognize the small but possible risk of HIV transmission by this activity. 
The reasons for the predominance of male homosexuals in the HIV-infected pool are not entirely clear. Factors such as multiple sexual partners, a high frequency of anal intercourse, and a relatively closed sexual community all contribute to this phenomenon, but, obviously, this disease is not limited to males with a homosexual life-style. Among heterosexuals, anal intercourse is not required for transmission, and vaginal intercourse appears capable of bidirectional transmission..$^{3,4}$ The efficiency of male-to-female transmission appears to be greater than female-to-male transmission, although it is impossible to assess the quantitative risk for single or multiple sexual encounters with an infected individual.

Intravenous transmission most frequently occurs among drug users who share their needles and syringes. The efficiency of this route is increased by the practice of repeatedly injecting and withdrawing blood during the act of drug self-administration. Recent study results have correlated seropositivity to the number of injections, the number of days of use of unsterile needles, and the frequency of injecting at "shooting galleries" (drug houses), rather than to the type or duration of intravenous drug use. ${ }^{5}$

Not surprisingly, the demographics of neonatal $\mathrm{HIV}$ infection are directly related to those seen in adults, with the majority of HIV-infected infants being born to intravenous drug users. The virus itself may be transmitted to the offspring by three possible routes: during pregnancy, through the maternal circulation; during labor and delivery, via fetal/maternal transfusion or ingestion of blood or other fluids; or through infected breast milk. Current data regarding the rate of perinatal transmission are conflicting, but they suggest that approximately $40 \%$ to $50 \%$ of infants born to infected mothers will become infected themselves. ${ }^{1}$

\section{Strategies for prevention}

Overall prevention strategies of HIV infection are based on reaching populations at risk and intervening with education, with the aim of ultimately modifying behavior. The basic message of prevention is outlined in Table $1 .^{6}$ This message, while outwardly straightforward, is formidably complex from the perspective of strategy selection and outcome assessment. The following sections discuss the pros and cons of a variety of preventive strategies for sexual, blood-borne, and perinatal transmission.

\section{Strategies to reduce HIV transmission}

Sexual transmission. The numerous strategies for the prevention of sexual transmission of HIV vary greatly in their practicality and efficacy. Clearly, abstinence is the most effective and preferred method, particularly for our youth, who have been demonstrating increasing sexual activity at younger and younger ages. However, serious doubts exist about how widely this technique will be practiced, especially by those individuals who already are sexually active.

Reducing the number of sexual partners is a way to lessen the statistical odds of encountering an HIV-infected sexual partner. We believe, however, that this method has been greatly overemphasized, because it is clear that HIV can be transmitted on an extremely limited, even one-time basis. Cutting down the number of sexual partners, particularly "casual encounters," can be falsely reassuring to those still practicing high-risk sexual techniques with only one or a limited number of partners. In fact, in areas of low incidence, we ${ }^{7}$ have demonstrated a lack of correlation between seropositivity and the number of sexual partners, which suggests that the nature of the sexual encounter is critically important. Still, this method can be a valuable adjunct in the overall preventative strategy.

Protective sex, or "safer sex," is a technique that has gained wide recognition among the lay public. It refers to practices that minimize or eliminate the exposure to bodily fluids during sexual activity. The details will be explained in the following section, but such techniques include the use of condoms and the avoidance of mutual contact between mucous membranes. As with any method, protective sex is only as effective as the diligence with which it is practiced. Condom use and the elimination or modification of certain sexual practices may be extremely difficult for some individuals to adopt, thereby minimizing their compliance. While protective sex appears to be the only way to decrease transmission for those who persist in sexual activity of a casual nature with multiple partners, it is not the total solution for HIV prevention.

Goedert ${ }^{8}$ has suggested that HIV antibody testing be used as a guide to sexual activity in place of protective sex. He has recommended that all persons who previously have been sexually active and who are considering engaging in a new sexual relationship undergo HIV antibody testing and counseling. This would result in one of three possibilities: First, both prospective partners theoretically could be antibody positive and, thus, both infected. (There is no data on the safety of sexual interaction between two infected persons from the viewpoint of disease progression, but there is no compelling evidence to suggest that they could not or should not have normal sexual relations.)

Second, one person could be antibody positive and the other antibody negative. In this situation, it would be absolutely imperative that protective 
TABLE 1. THE AIDS* PREVENTION MESSAGE TO THE COMMUNITY.

To stop needle-borne transmission:

Don't share unsterile needles or syringes

To stop sexual transmission:

If you are going to have sex, $\uparrow$ use the following guidelines to decrease your risk of infection

Absolutely safe

Mutually monogamous relationship $\ddagger$

Extremely safe

Noninsertive $\S$ sexual relations

Very safe

Insertive sexual relations using a condom" ${ }^{\prime}$ (and non-

Risky oxynol 9 spermicide)

Anything else

To stop perinatal transmission:

If you could have been exposed to HIV,* get tested for antibodies

If you are positive, don't become pregnant.

- AIDS indicates acquired immunodeficiency syndrome; HIV indicates human immunodeficiency virus.

+ Vaginal or rectal intercourse. Decreasing one's sexual partners will decrease the chance of being exposed to an infectious person.

¥ Assuming neither partner previously exposed or proved to be noninfected (by antibody test).

\& Excludes vaginal or rectal intercourse.

Condoms must be used properly at all times with all partners.

From Francis and Chin. ${ }^{6}$

sex be practiced if both persons still wish to become sexually active. Here the knowledge of serologic status could have great psychologic impact for enhancing compliance to a protective sex regimen.

Third, and most often, both persons will be seronegative. While there is an extremely small chance that one or both of these tests may be falsenegative, the vast majority $(>99 \%)$ truly will represent uninfected individuals. Therefore, relations can be as free and open as the couple wishes. Knowledge that both partners are uninfected by the AIDS virus could also provide added impetus for stable and monogamous relationships.

While this overall strategy may seem unromantic and cumbersome, it is, in our opinion, the preferred method of prevention, particularly among adults who have been sexually active. It makes no difference whether they are homosexuals, bisexuals, or heterosexuals - the strategy remains the same.

Such a strategy is justified by several lines of reasoning. For example, while protective sex is better than unprotective sex, it is not realistic for two persons who wish to engage in a stable, monogamous relationship to use such techniques for an extended period of time. Also, among adults, how confident can each partner be that he or she has never been intimate with a person in a high-risk group, or that no previous sexual contact has been intimate with someone at high risk? Because this question is impossible for most persons to answer definitively, the basing of a future sexual relationship on knowledge of serologic status makes increasing sense. It is, therefore, imperative that physicians become comfortable with the concept of HIV antibody testing and counseling in their office practices.

Blood-borne transmission. HIV can be transmitted through transfusion of contaminated blood or blood products, accidental needle stick, mucous membrane exposure to an infected body substance or, most commonly, the sharing of contaminated needles and syringes. With the adoption of universal body-substance isolation infection control procedures for all health-care workers, as recommended by the Centers for Disease Control, ${ }^{9}$ and the meticulous screening of blood donors and blood products by the blood banking community, these routes of transmission represent only a tiny fraction of the overall epidemic. This leaves the persistent, growing problem of HIV transmission among users of intravenous drugs.

This represents the most difficult problem of the AIDS epidemic, primarily because drug abuse is as much a social as a medical problem, and strategies aimed at treating only one aspect of this illness are doomed to failure. The possibility of HIV transmission serves to reemphasize the need for strong anti-drug campaigns, but recent history has taught us that such measures will be insufficient for totally curtailing these activities. In addition to representing a sizable portion of the HIV-infected pool, intravenous drug users are an important epidemiologic bridge to the heterosexual population and the source of the majority of cases of pediatric AIDS.

Prevention strategies must include group efforts to reduce the sharing of contaminated needle and syringes. Such programs have included educational materials or activities based at drug treatment centers or on the street. These have included information on how to clean "works" (drug-using paraphernalia) with bleach and water as well as strong encouragement not to share these materials.

Several European countries, as well as New York City, have instituted programs in which drug abusers can bring in contaminated needles and syringes in exchange for new ones. These programs are highly controversial and are not feasible in states where distribution of needles and syringes are illegal activities. Nevertheless, they are highly innovative and, therefore, it is extremely important to monitor them carefully for their success or failure.

We believe that HIV antibody testing and education of persons who are considering or using intravenous drugs can be extremely useful. For those 
who have never used drugs, a negative antibody test can be used to encourage them not to become involved in such activities. For those who currently are using drugs, whether they are positive or negative, counseling can offer an opportunity to seek treatment for drug addiction or, alternatively, to emphasize the avoidance of needle sharing and to advise how to sterilize needles and syringes should they persist in drug abuse.

Perinatal transmission. Strategies to prevent perinatal transmission are based on reaching out to high-risk teenagers and women to test and counsel them prior to their becoming pregnant. These are predominantly the wives or sexual partners of intravenous drug abusers or are themselves drug abusers; many of whom are prostitutes. However, even after reaching them, there is no guarantee that individual counseling and education will persuade them to avoid pregnancy. In fact, there are numerous examples of women in high-risk groups shunning such counseling.

Even more controversial are the issues surrounding identification of those HIV-infected persons who are already pregnant. Because $40 \%$ to $50 \%$ of their offspring will be HIV infected ${ }^{1}$ and the majority of infected infants will develop clinical disease, there are tremendous difficulties at present in providing compassionate care and placement for these children. Many physicians have advocated early abortion, but, as always, this position has raised ethical, moral, and religious objections, Antiabortionists stress that $50 \%$ or more of such offspring will be born uninfected.

\section{Overcoming obstacles to preventive education}

From the preceding discussion, it can be concluded that the AIDS epidemic would literally be over if all persons at risk were aware of whether they were HIV infected and then acted accordingly to prevent themselves or others from becoming infected. Obviously, this assumes that we can identify everyone at risk or, alternatively, test all individuals in our society repeatedly. It also assumes that we have an effective means for educating and ensuring unfailing behavioral modification.

While many may agree that it is the role of the US Public Health Service to test and educate our population and the role of our businesses, community groups, schools, and mass media to teach about prevention, there are numerous reasons why these institutions are unable to accomplish these tasks. In most major cities, the US Public Health Service has provided alternative test sites where individuals may seek confidential or anonymous HIV antibody testing and counseling. In reality, only a frac- tion of the potentially at-risk population has availed themselves of this service, and there are many problems surrounding further expansion of these public facilities. For example, many persons are reluctant to patronize public health facilities and, in certain cities, there are long waits to be tested. Furthermore, there is a certain degree of impersonalization and lack of a significant degree of quality control. Despite these reservations, these facilities have provided the frontline of preventive education for those at highest risk, particularly for those unable to pay for private care.

Educational programs based in the workplace, community groups, and schools are critically important but are not without inherent problems. Education in the schools or through the mass media is subject to strong institutional and social standards, which interfere with the clarity of the message that it conveys. These factors are particularly important in the more conservative areas of the country. The same criticisms can be rendered toward educational programs of employers, community groups, and religious groups, although all of these institutions are critically important for promoting AIDS education of a general nature to help foster an attitude of enlightenment and compassion throughout the community.

The physician/patient relationship offers an important additional forum for promoting AIDS education and prevention. Virtually all persons seek medical care at some point, thus providing an opportunity for direct, one-on-one education. In addition, the physician/patient interview is confidential and, therefore, is not restricted by the same social standards that affect other forums. Information regarding sexuality and drug abuse can be conveyed as clearly as needed to get the message across.

Theoretically, each and every patient coming under the care of a physician has a right and a need to be educated about AIDS. The majority of persons in our population, who are at no risk whatsoever for devloping HIV infection because of their personal life-styles, still need enough basic AIDS information to make responsible decisions for their schools, places of work, and communities.

The remainder of the population, who are at some finite risk for contracting HIV infection ( $\mathrm{Ta}-$ ble 2), must be given the information that can potentially save lives. This can most frequently be accomplished by HIV antibody testing and counseling provided in a thoughtful and professional manner.

To accomplish such broad educational objectives in the course of daily practice, there are numerous obstacles to overcome. We believe that there are strategies for individual physicians and groups of 
physicians to identify and overcome obstacles to effective AIDS education and prevention. These strategies include: (1) maintaining an adequate level of knowledge regarding HIV infection and related disorders, (2) identifying at-risk individuals in the patient population (taking a sexual history), and (3) overcoming fear and reluctance of patients to discuss AIDS.

\section{Staying abreast of medical and scientific aspects}

One of the most intimidating experiences for physicians is to be questioned by patients regarding late-breaking medical events that they are not aware of. In no area of medicine is there a greater potential for this to occur than AIDS. The mass media is full of AIDS news nearly every day, and it is difficult even for experts to be aware of every fact. Regardless, there are now numerous educational programs being presented by hospitals, medical societies, and others to make physicians and other health care professionals as knowledgeable as possible about AIDS. The American Osteopathic Association has pledged continuing education in this area; this series of articles is an example.

For these programs to be effective, physicians must avail themselves of them. Pressure placed upon them by their patients and their peers will assist in accomplishing the goals. Although AIDS is an exotic disease by scientific standards, it is not difficult to understand the basics of this illness and to share them with patients. Being candid with patients regarding late-breaking news is never a fault, and physicians should be willing to refer patients with such queries to local resources and hotlines that may be better equipped to discuss these matters.

\section{Identifying at-risk populations in clinical practice}

One of the greatest changes in the daily practice of medicine has been the increasing necessity for physicians to obtain detailed histories of sexual practices and drug use from every new patient. It is well known that most physicians are personally uncomfortable and reluctant to discuss matters of sexuality-let alone alternative sexual life-styleswith their patients. ${ }^{10}$ Most physicians who trained in the pre-AIDS epidemic era have little or no training in matters of sexuality and lack skills in sexual history taking.

The basis for successful history taking lies in a nonjudgmental manner. Patients must be approached in a nonthreatening way, and they must believe that divulging such information will not lessen the quality of their medical care or lead their physicians to think less of them. One technique that has been particularly successful for many phy-
TABLE 2. POPULATIONS AT INCREASED RISK FOR HIV INFECTION.

Homosexual or bisexual men

Intravenous drug users

Prostitutes

Sexually active immigrants from third world countries with a high incidence of AIDS

Recipients of blood and blood products before March 1985

Heterosexuals with more than one partner

Sexual contacts of persons at high risk

sicians starts by asking the patient, "Are you sexually active?" If the patient responds affirmatively, the physician asks, "Are your sexual activities with men, women, or both?" Such a line of questioning rarely is received in a suspicious or fearful manner, and, in our experience, it generally leads to a candid response. Avoiding questioning that includes the words homosexual or gay can be important, particularly with persons from certain ethnic groups or those who may frown on the social stigma of such life-styles, but who are actually engaging in homosexual activities.

It is also important to obtain candid histories of drug usage using appropriate terminology. We are aware of no uniformly successful technique for overcoming personal embarrassment or uneasiness in discussing such matters, but we have found that physicians who become accustomed to doing so generally overcome their own self inhibitions. Furthermore, realizing that such information is totally necessary for evaluating such common problems as fever, lymphadenopathy, headache, anemia, fatigue, weight loss, and diarrhea, provides added impetus for such historic data gathering.

\section{Overcoming patient's fear and reluctance to discuss AIDS}

There are numerous obstacles that patients must overcome to benefit from AIDS education. First, there is a known reluctance among male homosexuals to discuss matters of their life-style with physicians. In the pre-AIDS years, approximately half of all male homosexuals did not divulge their lifestyles to their doctors. Surprisingly, in a recent study, we found that this figure had not changed significantly even by 1987 , at least not in Northeastern Ohio (LH Calabrese, unpublished data). When male homosexuals in an earlier study ${ }^{10}$ were asked why they had not discussed sexual practices with their personal physicians, most responded that they were never asked or that they were fearful that they would suffer some loss of benefits because of this. Clearly, it is up to physicians to initiate these discussions.

Even persons who are not in the highest risk groups, but who have genuine interest in AIDS general information or prevention, are reluctant to dis- 
cuss such matters with their physician. Many feel that even mentioning AIDS will incriminate themselves as drug users or homosexuals or as being promiscuous.

Physicians can help to try to desensitize their patients as soon as they walk into the office. Lowcost or no-cost educational materials obtainable from many sources (Table 3 ) can be distributed in the waiting room, in the way physicians distribute materials on diet and fitness. In addition to pamphlets, there are numerous posters being produced by a variety of groups; these can be a form of visual cue to encourage patients to discuss these matters with their physician (Fig 1). The fear expressed by many physicians that displaying such materials will brand them as AIDS doctors and cause other patients to seek care elsewhere is totally unfounded in our experience. Most patients have a desire to gain more information about this disease, and they will gain confidence if they feel that their physician is knowledgeable and interested.

Once these obstacles are overcome, the physician must address the real challenge of AIDS, which is to identify individuals at high risk for HIV infection, offer HIV antibody testing, and, most important, provide detailed education and counseling to both carriers and noncarriers of the AIDS virus.

The rest of this review will focus on the proper use and interpretation of HIV antibody testing, as well as appropriate pre- and post-test counseling.

\section{Testing and counseling}

\section{Arenas for testing}

HIV antibody testing potentially can be beneficial in two major arenas of primary medical practicediagnostic testing and screening. Serologic results can assist in the establishment of a differential diagnosis, irrespective of patient acknowledgement of high-risk behaviors. For example, if a patient presents with unusual constitutional symptomatology, unexplained lymphadenopathy, hematologic abnormalities, or unexplained neurologic findings, with or without minor opportunistic infections such as thrush, herpes zoster, or hairy leukoplakia, antibody testing can help to rule out HIV-related illness. Other patients may exhibit frank symptoms of AIDS-related complex (ARC) or AIDS itself, and a definitive diagnosis can be made based on the results of antibody testing. The indications for this type of antibody testing are delineated clearly as adjunct methodologies used to establish or to clarify diagnosis of HIV-related illnesses. ${ }^{11}$

The obvious benefits of diagnostic HIV testing are apparent in the practical impact that it has on both patient care and prognosis of the presenting disorder. It is not, however, without risk. Pa-

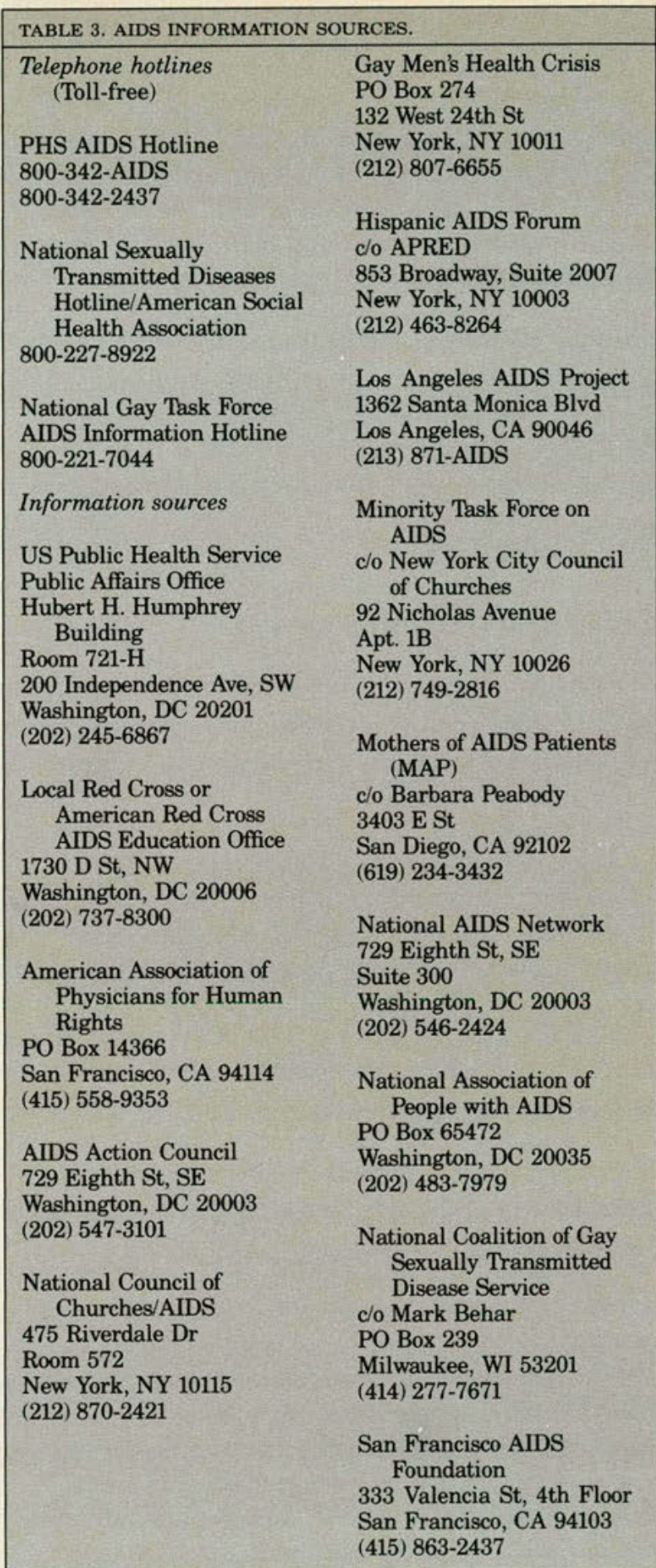

tients can suffer serious loss of benefits, such as housing, employment, and insurability, as well as educational opportunities, merely for undergoing this testing, regardless of results. ${ }^{12}$ Therefore, it is of utmost concern that patient confidentiality be maintained. Because of its serious negative implications, HIV antibody testing must be used only when reasonable medical judgment indicates its use. The results of the test must be guarded with 


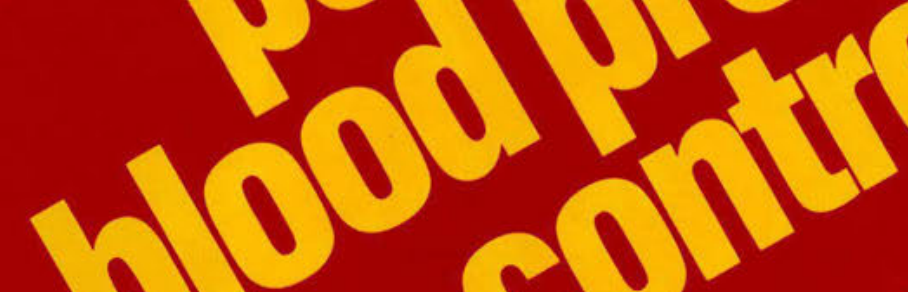

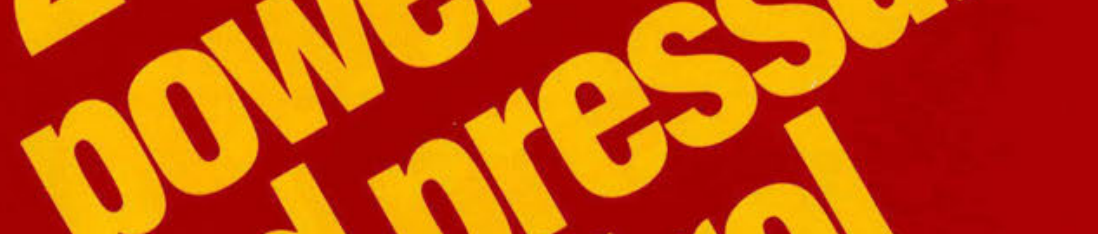

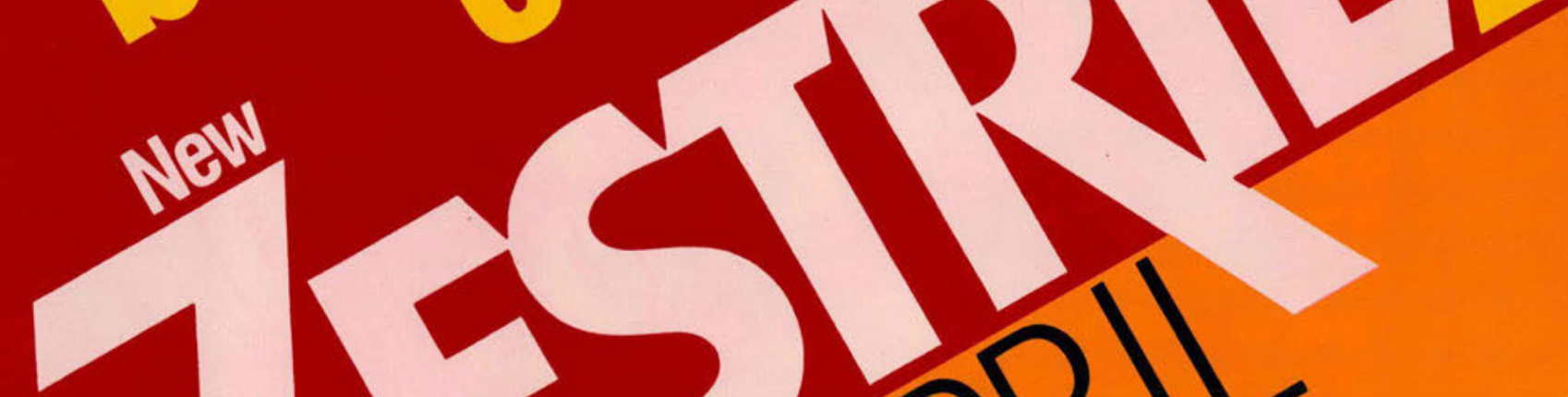

The antihypertensive effect may diminish at the end of the dosing interval.

Please see last page of this advertisement for brief summary of prescribing information. 


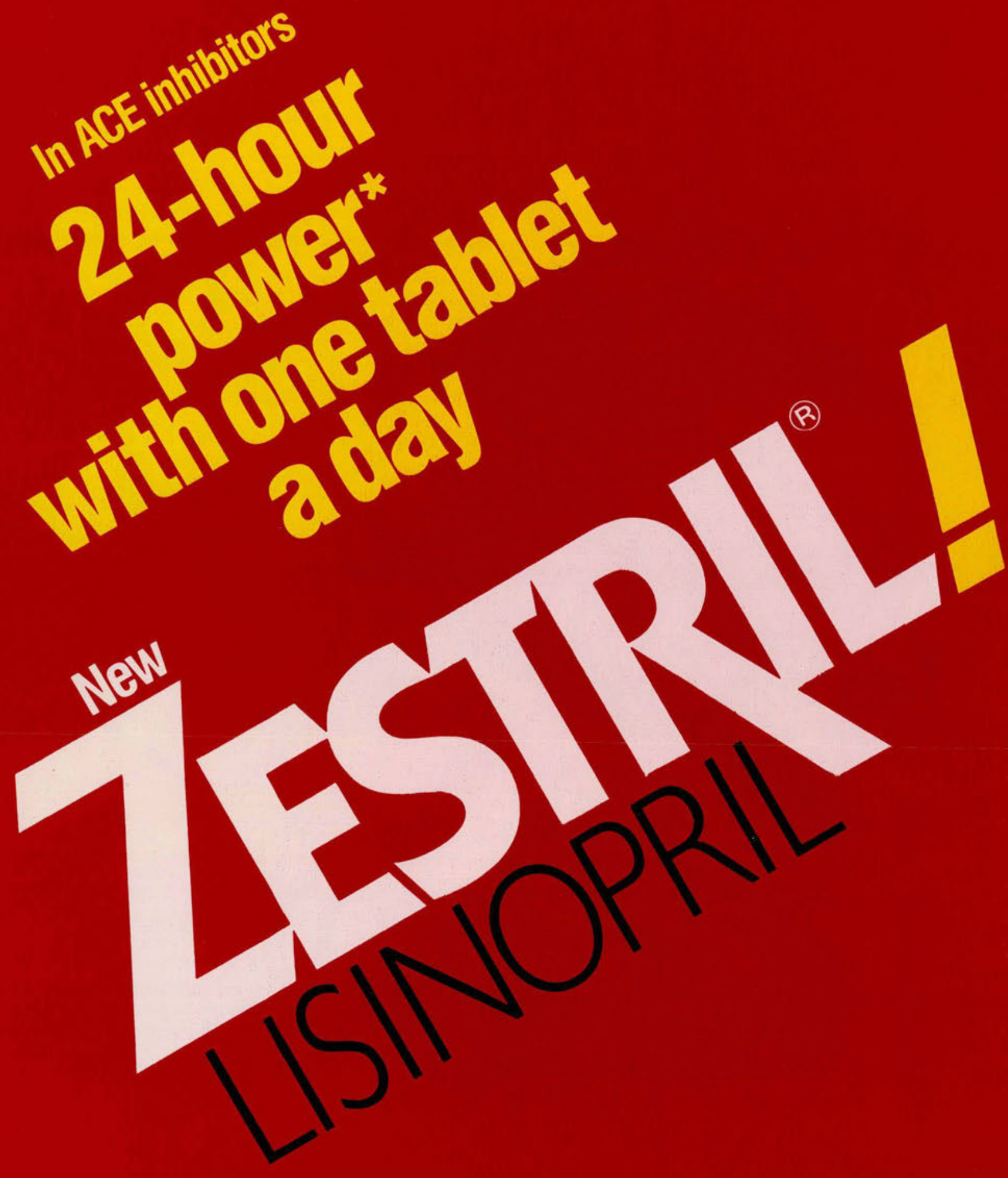

\section{Zestril: The long-acting ACE inhibitor}

Zestril achieves 24-hour blood pressure control with a half-life of 12 hours.' Angiotensin converting enzyme (ACE) inhibition ${ }^{+}$is long lasting with Zestrilsustained 24 hours after a single dose. ${ }^{2.4}$ The clinical significance of pharmacodynamic differences among ACE inhibitors in hypertensive patients has not been determined. 


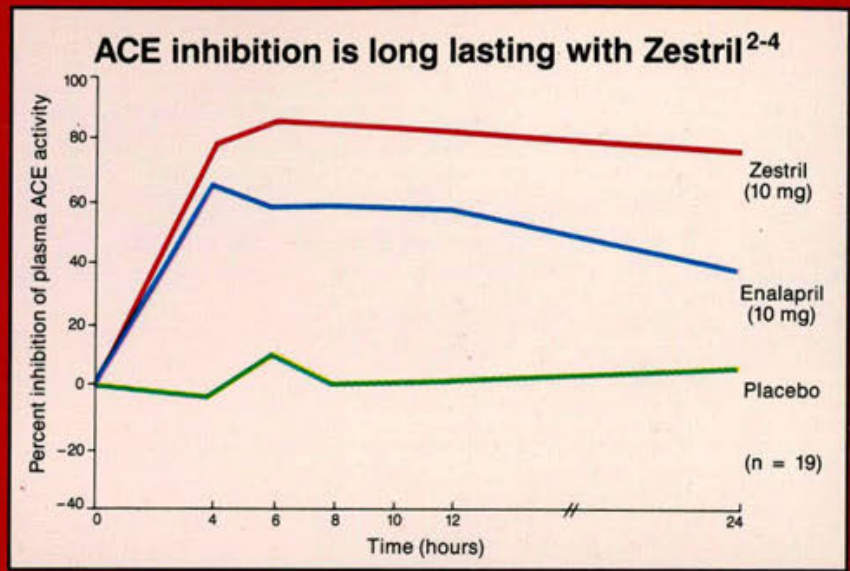

†In pharmacodynamic studies (utilizing $10 \mathrm{mg}$ of enalapril and lisinopril), ACE inhibition was significantly correlated to plasma renin activity and fall in diastolic blood pressure in normal volunteers.

- adapted from Ajayi et al, p $424^{2}$

\section{Zestril: Hypertensive patients start and stay at one tablet a day}

A single tablet of Zestril reduces blood pressure for 24 hours ${ }^{1}$ - unlike other ACE inhibitors, which may have to be increased to b.i.d. ${ }^{5}$ or t.i.d. ${ }^{6}$ dosing in some patients. The predictable once-daily dosage of Zestril enhances patient compliance and cost-effectiveness.

\section{Zestril: 24-hour blood pressure control that's easy to live with}

Zestril shares the low incidence of side effects characteristic of ACE inhibitors. Additionally, rash or taste disturbance are rarely seen with Zestril. What's more, Zestril is not metabolized by the liver? It is absorbed as the active drug and does not require bioactivation ${ }^{7}$-as needed with prodrugs such as enalapril. ${ }^{\ddagger 5,7}$ Absorption of Zestril is unaffected by food. ${ }^{8}$

Evaluation of the hypertensive patient should always include assessment of renal function. (See Dosage and Administration.) Angioedema has been reported with ACE inhibitors, including Zestril. (See Warnings.)

1988 ICI Americas Inc Now

The antihypertensive effect may diminish at the end f the dosing interval

Ilinical significance has not been determined in ypertensive patients.

lease see last page of this advertisement for rief summary of prescribing information. 
ZESTRIL ${ }^{*}$ (lisinopril)

INDICATIONS AND USAGE. Zestril is indicated for the treatment of hypertension. It may be used alone as initial therapy or concomitantly with other classes of antihypertensive agents. In using Zestril, consideration agranulocytosis, particularly in patients with renal impairment or collagen vascular disease, and that available data are insufficient to show that Zestril does not have a similar risk. (See WARNINGS.) CONTRAINDICATIONS. Zestril is contraindicated in patients who are hypersensitive to this product. WARNINGS. Angioedema: Angioedema of the face, extremities, lips, tongue, glottis and/or larynx has been reported in patients treated
with angiotensin converting enzyme inhibitors, including Zestril. In such cases, Zestril should be promptly discontinued, and the patient carefully observed until the swelling disappears. In instances where swelling has been confined to the face and lips the condition has generally resolved without treatment, although antihistamines have been useful in relieving symptoms. Angioedema associated with laryngeal edema may appropriate therapy, eg, subcutaneous epinephrine solution $1: 1000(0.3 \mathrm{~mL}$ to $0.5 \mathrm{~mL})$ should be promptly administered. (See ADVERSE REACTIONS.) Hypotension: Excessive hypotension was rarely seen in uncom plicated hypertensive patients but is a possible consequence of use with Zestril in salt/volume-depleted persons,
such as those treated vigorously with diuretics or patients on dialysis. (See PRECAUTIONS, Drug Interactions and ADVERSE REACTIONS.) In patients with severe congestive heart failure, with or without associated rena: insufficiency, excessive hypotension has been observed and may be associated with oliguria and/or progressive azotemia, and rarely with acute renal failure and/or death. Because of the potential fall in blood pressure in these patients, therapy should be started under very close medical supervision. Such patients should be Similar considerations apply to patients with ischemic heart or cerebrovascular disease in whom an excessive fall in blood pressure could result in a myocardial infarction or cerebrovascular accident. If hypotension occurs, the patient should be placed in supine position and, if necessary, receive an intravenous infusion of normal saline. A transient hypotensive response is not a contraindication to further doses which usually can be given
without difficulty once the blood pressure has increased after volume expansion. Neutropenia/Agranulocytosis: Another angiotensin converting enzyme inhibitor, captopril, has been shown to cause agranulocytosis and bone marrow depression, rarely in uncomplicated patients but more frequently in patients with renal impairment especially if they also have a collagen vascular disease. Available data from clinical trials of Zestril are insufficient
to show that Zestril does not cause agranulocytosis at similar rates. Periodic monitoring of white blood cell counts in patients with collagen vascular disease and renal disease should be considered. PRECAUTIONS. General. Impaired Renal Function: As a consequence of inhibiting the renin-angiotensin-aldosterone system, heart failure whose renal function may depend on the activity of the renin-angiotensin-aldosterone system, treatment with angiotensin converting enzyme inhibitors, including Zestril, may be associated with oliguria and/or progressive azotemia and rarely with acute renal failure and/or death. In hypertensive patients with unilateral or bilateral renal artery stenosis, increases in blood urea nitrogen and serum creatinine may occur. Experience with another angiotensin converting enzyme inhibitor suggests that these increases are usually reversible upon discontinuation of Zestril and/or diuretic therapy. In such patients, renal function should be monitored during the first few weeks of therapy. Some hypertensive patients with no apparent pre-existing renal vascular disease have developed increases in blood urea nitrogen and serum creatinine, usually minor occur in patients with pre-existing renal impairment. Dosage reduction of Zestril and/or discontinuation of the diuretic may be required. Evaluation of the hypertensive patient should always include assessment of potassium greater than $5.7 \mathrm{mEq} / \mathrm{L}$ ) occurred in approximately $2.2 \%$ of hypertensive patients and $4.0 \%$ o patients with congestive heart failure. In most cases these were isolated values which resolved despite continued therapy. Hyperkalemia was a cause of discontinuation of therapy in approximately $0.1 \%$ of hypertensive patients. Risk factors for the development of hyperkalemia include renal insuficiency, diabetes meilitus, and the substitutes, which should be used cautiously, if at all, with Zestril. (See Drug Interactions.) Surgery/Anesthesia: In patients undergoing major surgery or during anesthesia with agents that produce hypotension, Zestril may block angiotensin Il formation secondary to compensatory renin release. If hypotension occurs and is conAngioedema: Angioedema, including laryngeal edema, may occur especially following the first dose of Zestril. Patients should be so advised and told to report immediately any signs or symptoms suggesting angioedema (swelling of face, extremities, eyes, lips, tongue, difficulty in swallowing or breathing) and to take no more

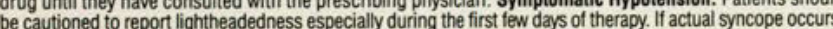
the patient should be told to discontinue the drug until they have consulted with the prescribing physician. All patients should be cautioned that excessive perspiration and dehydration may lead to an excessive fall in blood pressure because of reduction in fluid volume. Other causes of volume depletion such as vomiting or diarrhea may also lead to a fall in blood pressure; patients should be advised to consult with their physician their physician. Neutropenia: Patients should be told to report promptly any indication of intection (eg, sore throat, fever) which may be a sign of neutropenia. NOTE: As with many other drugs, certain advice to patients being treated with Zestril is warranted. This information is intended to aid in the safe and effective use of this medication. It is not a disclosure of all possible adverse or intended effects. Drug Interactions. Hypo-
tension - Patients on Diuretic Therapy: Patients on diuretics and especially those in whom diuretic therapy was recently instituted, may occasionally experience an excessive reduction of blood pressure after initiation of therapy with Zestril. The possibility of hypotensive effects with Zestril can be minimized by either discontinuing the diuretic or increasing the salt intake prior to initiation of treatment with Zestril. If it is necessary to continue the diuretic, initiate therapy with Zestril at a dose of $5 \mathrm{mg}$ daily, and provide medical supervision after the initial dose for at least two hours and until blood pressure has stabilized for at least an additional hour. (See Zestril, an additional antihypertensive effect is usually observed. Studies with ACE inhibitors in combination with diuretics indicate that the dose of the ACE inhibitor can be reduced when it is given with a diuretic. (See DOSAGE AND ADMINISTRATION.) Indomethacin: In a study in 36 patients with mild to moderate hypertension where the antihypertensive effects of Zestril alone were compared to Zestril given concomitantly with indomethacin, the use of indomethacin was associated with a reduced effect, although the difference between digoxin without evidence of clinically significant adverse interactions. No clinically important pharmacokinetic interactions occurred when Zestril was used concomitantly with propranolol or hydrochlorothiazide. The presence of food in the stomach does not alter the bioavailability of Zestril. Agents Increasing Serum Potassium: diuretics (eg, spironolactone, triamterene or amiloride), potassium supplements, or potassium-containing salt substitutes may lead to significant increases in serum potassium. Therefore, if concomitant use of these agents is indicated because of demonstrated hypokalemia, they should be used with caution and with frequent monitoring of serum potassium. Carcinogenesis, Mutagenesis, Impairment of Fertility. There was no evidence of a tumorigenic effect when lisinopril was administered for 105 weeks to male and female rats at doses up to $90 \mathrm{mg} / \mathrm{kg} /$ day (about 56 times ${ }^{*}$ the maximum recommended daily human dose) or when lisinopril was maximum recommended daily human dose). "Based on patient weight of $50 \mathrm{Kg}$. Lisinopril was not mutagenic in the Ames microbial mutagen test with or without metabolic activation. It was also negative in a forware mutation assay using Chinese hamster lung cells. Lisinopril did not produce single strand DNA breaks in an in vitro alkaline elution rat hepatocyte assay. In addition, lisinopril did not produce increases in chromosoma aberrations in an in vitro test in Chinese hamster ovary cells or in an in vivo study in mouse bone marrow. $300 \mathrm{mg} / \mathrm{kg} /$ day of lisinopril. Pregnancy. Pregnancy Category C: Lisinopril was not teratogenic in mice treated on days 6-15 of gestation with up to $1,000 \mathrm{mg} / \mathrm{kg} / \mathrm{day}$ (625 times the maximum recommended human dose). There was an increase in fetal resorptions at doses down to $100 \mathrm{mg} / \mathrm{kg}$; at doses of $1,000 \mathrm{mg} / \mathrm{kg}$ this was prevented by saline supplementation. There was no fetotoxicity or teratogenicity in rats treated with up to receiving lisinopril from day 15 of gestation through day 21 postpartum, there was an increased incidence in pup deaths on days 2.7 postpartum and a lower average body weight of pups on day 21 postpartum. The increase in pup deaths and decrease in pup weight did not occur with maternal saline supplementation Lisinopril, at doses up to $1 \mathrm{mg} / \mathrm{kg} / \mathrm{day}$, was not teratogenic when given throughout the organogenic period to eliminate maternotoxic effects and enable evaluation of the teratogenic potential at the highest possible dosage level. The rabbit has been shown to be extremely sensitive to angiotensin converting enzyme inhibitors (captopril and enalapril) with maternal and fetotoxic effects apparent at or below the recommended therapeutic at a dose of lisinopril at $1 \mathrm{mg} / \mathrm{kg} / \mathrm{day}$ and by an increased incidence of incomplete ossification at the lowest dose tested ( $(0.1 \mathrm{mg} / \mathrm{kg} / \mathrm{day}$ ). By whole body autoradiography, radioactivity was found in the placenta following administration of labeled lisinopril to pregnant rats, but none was found in the fetuses. There are no adequate and well-controlled studies in pregnant women. Zestril should be used during pregnancy only if the potentia following administration of ${ }^{4 A} \mathrm{C}$ lisinopril. It is not known whether this drug is excreted in human milk.
ZESTRIL ${ }^{\circ}$ (lisinopril)

Because many drugs are excreted in human milk, caution should be exercised when Zestril is given to a nursin mother. Pediatric Use: Safety and effectiveness in children have not been established. ADVERASE REACTIONS
Zestril has been found to be generally well tolerated in controlled clinical trials involving 2003 patients an zestril has been found to be generally well tolerated in controlled clinical trials involving 2003 patients an
subiects. The most frequent clinical adverse experiences in controlled trials were dizziness $(6.3 \%)$, headach

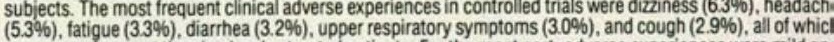
were more frequent than in placebo-treated patients. For the most part, adverse experiences were mild an fransient in nature. Discontinuation of therapy was required in $6.0 \%$ of patients. In clinical trials, the overa dosage range. For adverse experiences which occurred in more than $1 \%$ of patients and subjects treate listed in the table below. Percent of Patients in Controlled Studies

\begin{tabular}{|c|c|c|c|}
\hline & $\begin{array}{c}\text { Zestril } \\
\text { ( }=2003 \dagger) \\
\text { Incidence } \\
\text { (discontinuation) }\end{array}$ & $\begin{array}{c}\text { Zestril/Hydrochlorothiazide } \\
(\mathrm{n}=644) \\
\text { Incidence } \\
\text { (discontinuation) }\end{array}$ & $\begin{array}{c}\text { Placebo } \\
(n=207) \\
\text { Incidence }\end{array}$ \\
\hline $\begin{array}{l}\text { Dizziness } \\
\text { Headache } \\
\text { Fatigue } \\
\text { Diarrhea } \\
\text { Upper Respiratory Symptoms } \\
\text { Cough } \\
\text { Nausea } \\
\text { Hypotension } \\
\text { Rash } \\
\text { Orthostatic Effects } \\
\text { Asthenia } \\
\text { Chest Pain } \\
\text { Vomiting } \\
\text { Dyspnea } \\
\text { Dyspepsia } \\
\text { Paresthesia } \\
\text { Impotence } \\
\text { Muscle Cramps } \\
\text { Back Pain } \\
\text { Nasal Congestion } \\
\text { Decreased Libido } \\
\text { Vertigo }\end{array}$ & $\begin{array}{l}6.3(0.6) \\
5.3(0.2) \\
3.3(0.2) \\
3.2(0.3) \\
3.0(0.0) \\
2.9(0.4) \\
2.3(0.3) \\
1.8(0.8) \\
1.5(0.4) \\
1.4(0.0) \\
1.3(0.4) \\
1.3(0.1) \\
1.3(0.2) \\
1.1(0.0) \\
1.0(0.0) \\
0.8(0.0) \\
0.7(0.2) \\
0.6(0.0) \\
0.5(0.0) \\
0.3(0.0) \\
0.2(0.1) \\
0.1(0.0)\end{array}$ & $\begin{array}{l}9.0(0.9) \\
4.3(0.5) \\
3.9(0.5) \\
2.6(0.3) \\
4.5(0.0) \\
4.5(0.8) \\
2.5(0.2) \\
1.6(0.5) \\
1.6(0.2) \\
3.4(0.2) \\
2.0(0.2) \\
1.2(0.2) \\
1.4(0.0) \\
0.5(0.2) \\
1.9(0.0) \\
2.0(0.2) \\
1.6(0.3) \\
2.8(0.6) \\
1.1(0.0) \\
1.2(0.0) \\
1.2(0.0) \\
1.1(0.2)\end{array}$ & $\begin{array}{l}1.9 \\
1.9 \\
1.0 \\
2.4 \\
0.0 \\
1.0 \\
2.4 \\
0.5 \\
0.5 \\
1.0 \\
1.0 \\
1.4 \\
0.5 \\
1.4 \\
0.0 \\
0.0 \\
0.0 \\
0.5 \\
1.4 \\
0.0 \\
0.0 \\
0.0\end{array}$ \\
\hline
\end{tabular}

diuretic therapy.

diuretic therapy.

Dossibly drug related events reported in uncontrolled studies or marketing experience included: BODY A AWHOLE: Chest discomfort, fever, flushing. CARDIOVASCULAR: Angina pectoris, orthostatic hypotensior rhythm disturbances, tachycardia, peripheral edema, palpitation. DIGESTIVE: Abdominal pain, anorexia, cor stipation, flatulence. METÁBOLISM: Gout. MUSCULOSKELETAL: Joint pain, shoulder pain. NERVOUS SYS TEMPSYCHIATRIC: Depression, somnolence, insomnia, stroke. RESPIRATORY SYSTEM: Bronchitis, sinusitis
pharyngeal pain. UROGENITAL: Oliguria, progressive azotemia, acute renal failure. OTHER: Blurred vision pharyngeal pain. UROGENITAL: Oliguria, progressive azotemia, acute renal tailure. OTHER: Blurred vision
pruritus, urinary tract infection, vasculitis of the legs. ANGIOEDEMA: Angioedema has been reported in patient pruritus, urinary tract infection, vasculitis of the legs. ANGIOEDEMA: Angioedema has been reported in patien:
receiving Zestril $(0.1 \%)$. Angioedema associated with laryngeal edema may be fatal. If angioedema of th face, extremities, lips, tongue, glottis and/or larynx occurs, treatment with Zestril should be discontinue face, extremities, lips, tongue, glottis and/or larynx occurs, treatment with Zestril should be discontinue
and appropriate therapy instituted immediately. (See WARNINGS.) HYPOTENSION: In hypertensive patient: hypotension occurred in $1.2 \%$ and syncope occurred in $0.1 \%$ of patients. Hypotension or syncope was cause of discontinuation of therapy in $0.5 \%$ of hypertensive patients. (See WARNINGS.) In patients wit
congestive heart failure, hypotension occurred in $5.0 \%$ and syncope occurred in $1.0 \%$ of patients. Thes adverse experiences were causes for discontinuation of therapy in $13 \%$ of these patients. Clinical Laborato Test Findings. Serum Electrolytes: Hyperkalemia (See PRECAUTIONS.) Creatinine, Blood Urea Nitroget Minor increases in blood urea nitrogen and serum creatinine, reversible upon discontinuation of therapy, wer
observed in about $2.0 \%$ of patients with essential hypertension treated with Zestril alone. Increases wer more common in patients receiving concomitant diuretics and in patients with renal artery stenosis. (SE more common in patients receiving concomitant diuretics and in patients with renal artery stenosis. (S
PRECAUTIONS.) Reversible minor increases in blood urea nitrogen and serum creatinine were observed approximately $9.1 \%$ of patients with congestive heart failure on concomitant diuretic therapy. Frequent! these abnormalities resolved when the dosage of the diuretic was decreased. Hemoglobin and Hematocr Small decreases in hemoglobin and hematocrit (mean decreases of approximately $0.4 \mathrm{~g} \%$ and $1.3 \mathrm{vol} \%$ respectively) occurred frequently in patients treated with Zestril but were rarely of clinical importance in patien
without some other cause of anemia. In clinical trials, less than $0.1 \%$ of patients discontinued therapy du without some other cause of anemia. In clinical trials, less than $0.1 \%$ of patients discontinued therapy du
to anemia. Other (Causal Relationship Unknown): Rarely, elevations of liver enzymes and/or serum bilirub have occurred. Overall, $2.0 \%$ of patients discontinued therapy due to laboratory adverse experiences, principal elevations in blood urea nitrogen $(0.6 \%)$, serum creatinine $(0.5 \%)$, and serum potassium $(0.4 \%)$. OVERDOSAG
The oral $L D_{50}$ of lisinopril is greater than $20 \mathrm{~g} / \mathrm{kg}$ in mice and rats. The most likely manifestation of ove dosage would be hypotension, for which the usual treatment would be intravenous infusion of normal salin
solution. DOSAGE AND ADMINISTRATION. Initial Therapy: In patients with uncomplicated essential hype solution. DOSAGE AND ADMINISTRATION. Initial Therapy: In patients with uncomplicated essential hype
tension not on diuretic therapy, the recommended initial dose is $10 \mathrm{mg}$ once a day. Dosage should be adjuste tension not on diuretic therapy, the recommended initial dose is $10 \mathrm{mg}$ once a day. Dosage should be adjuste
according to blood pressure response. The usual dosage range is $20-40 \mathrm{mg}$ per day administered in a sing according to blood pressure response. The usual dosage range is $20-40 \mathrm{mg}$ per day administered in a sing
daily dose. The antihypertensive effect may diminish toward the end of the dosing interval regardless of th administered dose, but most commonly with a dose of $10 \mathrm{mg}$ daily. This can be evaluated by measuring bloc pressure just prior to dosing to determine whether satisfactory control is being maintained for 24 hours. to give greater effect. If blood pressure is not controlled with Zestril alone, a low dose of a diuretic may added . diuretic, it may be possible to reduce the dose of Zestril. Diuretic Treated Patients: In hypertensive patien diuretic, it may be possible to reduce the dose of Zestril. Diuretic Treated Patients: In hypertensive patien
who are currently being treated with a diuretic, symptomatic hypotension may occur occasionally followir who are currently being treated with a diuretic, symptomatic hypotension may occur occasionally followi
the initial dose of Zestril. The diuretic should be discontinued, if possible, for two or three days before beginnir the initial dose of Zestril. The diuretic should be discontinued, if possible, for two or three days betore beginni
therapy with Zestril to reduce the likelihood of hypotension. (See WARNINGS.) The dosage of Zestril shou be adjusted according to blood pressure response. If the patient's blood pressure is not controlled with Zest alone, diuretic therapy may be resumed as described above. If the diuretic cannot be discontinued, an init
dose of $5 \mathrm{mg}$ should be used under medical supervision for at least two hours and until blood pressure hdose of $5 \mathrm{mg}$ should be used under medical supervision for at least two hours and until blood pressure ha
stabilized for at least an additional hour. (See WARNINGS and PRECAUTIONS, Drug Interactions.) Concomita stabilized for at least an additional hour. (See WARNINGS and PRECAUTIONS, Drug interactions.) Concomita administration of Zestril with potassium supplements, potassium salt substitutes, or potassium-spari
diuretics may lead to increases of serum potassium. (See PRECAUTIONS.) Use in Elderly: In general, blo pressure response and adverse experiences were similar in younger and older patients given similar dosi
of Zestril. Pharmacokinetic studies, however, indicate that maximum blood levels and area under the plas concentration time curve (AUC) are doubled in older patients so that dosage adjustments should be ma with particular caution. Dosage Adjustment in Renal Impairment: The usual dose of Zestril $(10 \mathrm{mg})$ recommended for patients with creatinine clearance $>30 \mathrm{~mL} / \mathrm{min}$ (serum creatinine of up to approximate
$3 \mathrm{mo} / \mathrm{dL}$ ). For patients with creatinine clearance $>10 \mathrm{~mL} / \mathrm{min} \leq 30 \mathrm{~mL} / \mathrm{min}$ (serum creatinine $\geq 3 \mathrm{mg} / \mathrm{dL}$ $3 \mathrm{mg} / \mathrm{dL}$ ). For patients with creatinine clearance $>10 \mathrm{~mL} / \mathrm{min} \leq 30 \mathrm{~mL} / \mathrm{min}$ (serum creatinine $\geq 3 \mathrm{mg} / \mathrm{dL}$
the first dose is $5 \mathrm{mg}$ once daily. For patients with creatinine clearance $<10 \mathrm{~mL} / \mathrm{min}$ (usually on hemodialysi or to a maximum of $40 \mathrm{mg}$ daily.
of

\begin{tabular}{|lcc|}
\hline Renal Status & Creatinine-Clearance mL/min & Initial Dose mg/day \\
\hline $\begin{array}{l}\text { Normal Renal Function to Mild Impairment } \\
\text { Moderate to Severe Impairment }\end{array}$ & $>30$ & 10 \\
Dialysis Patients & $\geq 10 \leq 30$ & 5 \\
\hline
\end{tabular}

¥Dosage or dosing interval should be adjusted depending on the blood pressure response. Rev E 12 Distributed by: Stuart Pharmaceuticals, Division of ICI Americas Inc, Wilmington, DE 19897. REFERENCES: 1. Zestrile (lisinopril) full prescribing information issued December 1987. 2. Aiayi AA, Campbell E Keiman AW, et al: Pharmacodynamics and population pharmacokinetics of enalapril and lisinopril. Int $J$ Clin Pharma
Res 1985; $5(6): 419-427.3$. Millar JA, Derix FHM. McLean K, et al: Pharmacodynamics of converting enzyme inhibiti The cardiovascular, endocrine and autonomic effects of MKA21 (enalaprl) and MKK21. Br J Clin Pharmacol 1982; 14:347.3.
4. Hodsman GP, Zabludowski JR, Zoccali C, et al: Enalapril (MK421) and its lysine analogue (MK521): A comparis 4. Hodsman GP, Zabludowski JR, Zoccali C, et al: Enalapril (MK421) and its lysine analogue (MK521): A comparis
of acute and chronic effects on blood pressure, renin-angiotensin system and sodium excretion in normal man. Br $J C$

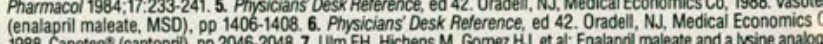
1988. Capoten" (captopri), pp 2046-2048. 7. Ulm EH, Hichens M, Gomez HJ, et al: Enalapril maleate and a lysine analog
(MK-521): Disposition in man. BrJ CClin Pharmacol 1982:14:357.362. 8. Mojaverian P. Rocci ML Jc. Vlasses PH, et Effect of food on the bioavailability of lisinopril, a nonsulfhydryl angiotensin-converting enzyme inhibitor. JPharm

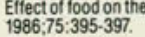


a heightened level of confidentiality above that used for general patient-related information. Results should be protected except where required by law. At present, it is not recommended that diagnostic HIV antibody serology be used as an infection control device. ${ }^{13}$

HIV antibody testing also should be used in general patient screening, with the goal of decreasing transmission either by not utilizing blood or organs from infected donors or as an adjunct to antitransmission counseling. Indications for this type of testing are based on recommendations of the Centers for Disease Control. ${ }^{11}$

Those to be tested include, but are not limited to, the following: all blood, semen, and organ donors; all persons who have engaged in high-risk behaviors who are being admitted to a hospital with possible HIV-related illness; homosexual and bisexual men; individuals who may have sexually transmitted diseases; male and female prostitutes; intravenous drug users, especially those who have shared needles; high-risk persons planning marriage; women of childbearing age who are contemplating pregnancy; neonates, especially those with parents who have a history of high-risk behaviors; persons who have received multiple transfusions of blood or blood products, especially prior to March 1985; those incarcerated in correctional institutions; heterosexuals who have had multiple (now defined as more than one) sexual partners since 1978; sexually active third world immigrants, especially those from high endemic areas of HIV infection; and, in general, persons who consider themselves at risk for this infection.

Because of the potentially large segment of the population, meeting these general testing guidelines and the test's implied repercussions, it is necessary to address provisions that should be met by screening programs (Table 4). Programs designed for general screening should be voluntary, and those to be tested should be prepared psychologically for the potential of positive results. Laboratory services should demonstrate a high level of technical accuracy, and test results, risk behavior assessment, and demographic data collected should be considered confidential (unless reportable by law). Most important, all test sites, both public and private, must have high-quality, comprehensive counseling programs associated with them. To offer testing without integral counseling services ignores the opportunity to engage individuals in active risk reduction education at the time they seek personal antibody serologic status. ${ }^{12}$

General screening programs allow individuals to become cognizant of their serostatus. With concomitant counseling and health education, they

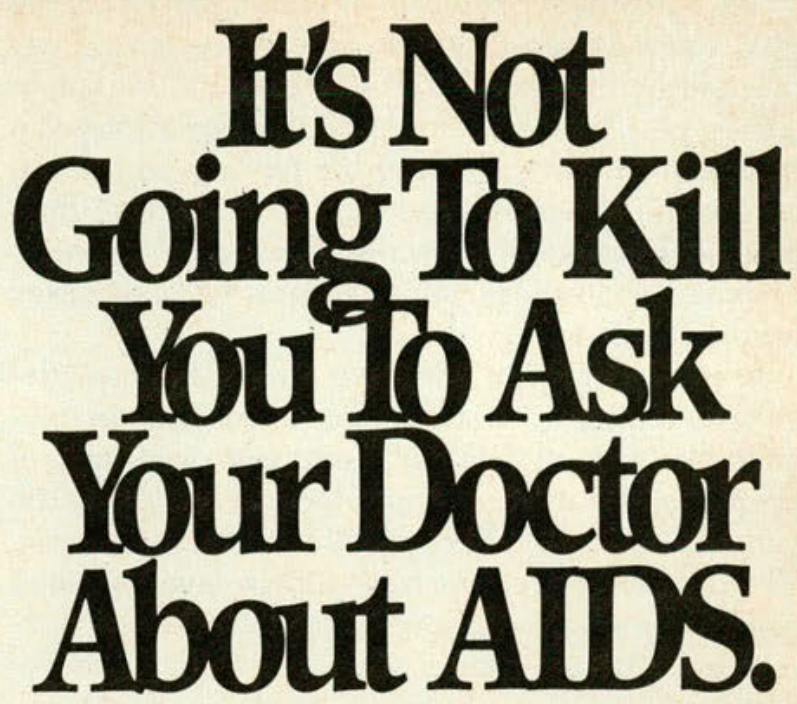

Not Asking Might.

Fig 1. This poster is provided by the Academy of Medicine, Cleveland, for use in physicians' offices.

also afford medical professionals the opportunity to influence behaviors that have an effect on the horizontal transmission of this disease. Explicit behavioral changes, notifications of associated contacts, and identification of conjunctive follow-up care are essential for seropositive individuals. Seronegative persons require additional information on methodologies to avoid possible exposure and infection. ${ }^{11}$

One potential detriment to screening is the false sense of security it offers. If a positive client is tested prior to the time necessary for antibody formation, a false-negative test would result. As with any testing, if the window of opportunity is missed, false reassurance based on erroneous test results can ensue. Also, some persons found to be negative gain false reassurance and feel immune from the negative consequences of continued high-risk practices.

The downside of general screening stems from the potential social ostracism associated with positive test findings and the discriminatory loss of benefits. It is possible that false-positive results may follow the social sequelae of those with true findings. Some individuals have suffered extreme psychologic stress (to the point of suicide) from having to face the prospect of an uncertain prognosis associated with positive test results. ${ }^{14,15}$

\section{Commerical HIV test kits}

In the spring of 1985, the Food and Drug Admini- 
stration licensed the first commercially available HIV antibody serology test, an enzyme-linked immunosorbent assay (ELISA). Today it is used to screen all blood, semen, and organ donations and has been employed in both the public and private sectors for diagnostic as well as screening purposes. ${ }^{11}$ Because of its widespread, sometimes indiscriminate, use, questions regarding its accuracy and usefulness have arisen.

It is important to note that the ELISA was developed originally to screen blood donations for possible infection by HIV, thus offering a measure of protection against contaminated units entering the general donor pool. Because of its intended use, the ELISA was designed to have a high level of sensitivity, while lacking specificity. ${ }^{11}$ These parameters must be considered when examining test results.

It is strongly recommended that whenever a reactive or positive ELISA is obtained, the test should be repeated in duplicate using the original serum on the next test kit run to act as quality assurance of the original findings. At the retrovirus laboratory of the Cleveland Clinic Foundation, if any two of the three runs are reactive, it is necessary to run a secondary test that is confirmatory in nature, such as the Western Blot test. This test not only has the sensitivity of ELISA, but it has greater specificity to HIV viral proteins. If both the repeat ELISA and Western Blot tests are read as reactive/ positive, the results have a high predictive value, with an accuracy rate $>99 \% .^{11}$

Some possible pitfalls are associated with HIV antibody tests. If a positive sample is obtained too soon after infection, seroconversion may not have yet occurred, and the test result would be negative. It takes approximately 9 to 12 weeks after infection for antibody formation to reach a reactive level on the ELISA. In rare cases, it may take as long as 16 weeks to seroconvert. ${ }^{16}$ In still fewer instances, perhaps $1 \%$ or less, infected individuals may never yield reactive/positive test results. It is generally agreed that these cases are rare. ${ }^{16}$

Because of a loss of certain antigens during the purification processes, a person's serum may react in one manufacturer's ELISA and not in another's. If the person has not developed the full spectrum of antibodies, a false-negative or indeterminate reading results, because the antigens are underrepresented in quality or quantity in that given test system. ${ }^{16}$ Likewise, if a person is infected with an HIV variant, antibody reactivity to the HIV component in the test may be minimal. ${ }^{16}$ Therefore, it is difficult to assess test results without knowing the history of high-risk behaviors, which can help to sort out otherwise indeterminate findings.
TABLE 4. HIV ANTIBODY SCREENING GUIDELINES.

(1) All testing should be voluntary.

(2) Clients must be prepared psychologically for testing.

(3) Risk behavior assessments, demographic data, and results must be confidential (unless reportable by law).

(4) Laboratory services should demonstrate high technical accuracy.

(5) All testing sites must have comprehensive counseling services.

TABLE 5. RATIONALES FOR HIV TESTING AND SCREENING.

Fear

Patients often fear having been infected with HIV.

Diagnosis

Testing is performed to determine the cause of presenting symptoms.

Screening

The person desires to check personal serostatus.

Mandate

Testing is required for all emigres to the US and for military recruits.

Shortly after the test kits became available, a variety of testing sites emerged. These included public health clinics, physicians' offices, hospitals, and clinics. They offered the opportunity to be screened for possible HIV infection acquired through certain high-risk behavioral practices. ${ }^{17}$ As a result of this widespread use of antibody serology tests, numerous questions regarding appropriate use in this milieu have been posed. These questions are best dealt with when adequate information regarding client risk behaviors and a knowledge base are available. Therefore, it is imperative that all HIV testing programs provide adequate pre- as well as post-test counseling services. ${ }^{15,18}$

\section{Pre-test health education and counseling}

The pre-test counseling session should ascertain the reason why the patient is seeking testing services (Table 5). This is accomplished by an in-depth general information interview. Patients can be asked broad, open-ended questions regarding reasons for testing, risk-behavior history, and knowledge of HIV transmission modes. It is important that the client be made comfortable with this personal line of inquiry. It also is extremely important to discuss candidly, in a nonjudgmental manner, behaviors that may place the individual at risk. ${ }^{19}$

The indications for serologic testing also should be addressed at this time. Patients often have the mistaken notion that this is an AIDS test rather than an indirect method to ascertain infection by HIV. They must be made aware not only of the uses of the test but what the results indicate. They may assume incorrectly that a positive test auto- 


\begin{tabular}{|ll|}
\hline TABLE 6. SAFER SEX GUIDELINES. \\
\hline Safest: & Abstinence, no sexual activity. \\
Safe: & $\begin{array}{c}\text { Long-term monogamous relationship } \\
\text { (more than 10 years). } \\
\text { Fantasy, touching, mutual masturba- } \\
\text { tion, dry kissing. } \\
\text { Repeat negative serostatus for both sex- } \\
\text { ual partners. } \\
\text { Wet kissing, oral sex (male) with a con- } \\
\text { dom. } \\
\text { Vaginal intercourse with a condom. } \\
\text { Oral sex without a condom, either male } \\
\text { or female, masturbation on broken } \\
\text { skin. } \\
\text { Oral sex, either male or female, with a } \\
\text { condom. } \\
\text { Oral sex with a woman. } \\
\text { Anal-receptive or anal-insertive inter- } \\
\text { course with a condom. } \\
\text { Anything else, including, but not lim- } \\
\text { ited to: } \\
\text { Anal-receptive or anal-insertive inter- } \\
\text { course without a condom, } \\
\text { Internal watersports, vaginal sex with- } \\
\text { out condom, fisting, or rimming } \\
\text { (oral/anal contact), } \\
\text { Use of alcohol, amphetamines, amyl ni- } \\
\text { trate, cocaine, marijuana, or any } \\
\text { other drug, because of the effect it } \\
\text { has on judgment. }\end{array}$ \\
\hline
\end{tabular}

matically means that ARC or AIDS is inevitable. They usually expect to become symptomatic within an unreasonably short period of time (that is, days to weeks).

Often, individuals are extremely anxious or guilty about behaviors that they may have engaged in. Frequently, because of misunderstanding of modes of transmission, clients present with the perception of an acute need to be tested. In these cases, merely educating people about routes of transmission and methods of risk reduction may be all that is necessary.

Clients also must be informed of the possible negative consequences of having this test performed. The idea of true informed consent cannot be stressed strongly enough. Many persons presenting for testing have little or no idea of the possible negative sequelae encountered by some who have been tested. Again, it is necessary to stress the importance of a heightened level of confidentiality in the testing process.

Assessment of psychologic coping mechanisms also is vitally important. Asking how a patient might react to a positive test can elicit information about the possible negative psychosocial effects that test results may trigger. Appropriate intervention should be available to those who may require it. This may be accomplished by appropriate referral to public mental health clinics or to other qualified professionals. Some individuals ex- perience high stress levels during the waiting period between the initial visit and the test results. Support for these patients is an integral part of the testing process. Unfortunately, it is a frequently neglected area.

Today, many cities have HIV-related support groups to which clients can be referred (Table 3 ). These groups most often are guided by persons knowledgeable in the area of both HIV-related illness and appropriate support principles. It is strongly recommended that these groups be used, because they can offer a great deal of help to distressed persons.

In order to enhance patient compliance with recommended behavioral changes, patients must be made to feel that their questions will be considered important and answered as accurately and completely as current knowledge allows. This can best be accomplished by allowing adequate time to encourage clients to address any concerns they might feel particularly anxious or uncomfortable about. A second method to assist this process is to provide patients with written material that they may take with them. This often decreases their anxiety level by providing information that they can refer back to when the health professional is not available. A local or national AIDS hotline phone number also is helpful, because it allows individuals to have questions answered even when the physician or counselor may not be available. Primarily, it is important to create an atmosphere of openness and trust between yourself and the patient to enhance the communication of necessary information.

\section{Post-test health education and counseling}

The post-test counseling session offers opportunities to reinforce the behavioral modification necessary to enhance abililites to avoid infection with $\mathrm{HIV}$. If the test result is negative, it must be made clear that this status can be maintained so long as the client chooses to remain negative. The idea of HIV infection as a biobehavioral disease must be strongly reinforced. ${ }^{20}$ Reduction in risk behaviors, such as adoption of safer sex guidelines ${ }^{21,22}$ or enrollment in a drug treatment program, as well as reinforcement of behavioral changes, are an essential part of any post-test counseling program. ${ }^{18}$

If, however, the patient's results are positive, information about self protection as well as prohibition of virus transmission is of tantamount importance. Treatment of drug addiction, or at least elimination of needle sharing, is necessary. If addiction treatment is refused, teaching the patient how to clean the "works" (needle and syringe) to avoid transmission is desirable-if not altogether palatable to health professionals. 
The teaching of safer sex guidelines (Table 6) must be explicitly spelled out in clear, precise language. It is essential that persons who indicate that they will continue to be sexually active be informed that short of abstinence, there is no true safe sex. As health professionals, it is our duty to educate individuals about sexual activities that are of lower risk that also facilitate the normal expression of love and affection, which is such a vital part of human existence.

Frequent questioning to ascertain that the recommendations are clearly understood is essential. It is imperative that the patient rigidly follow risk reduction guidelines to avoid the possibility of acquiring sexually transmitted diseases, or reinfection by other strains of HIV through other known high-risk behavior.

Notification of current and past sexual contacts is strongly recommended. Patients may requires the health professional's assistance with this cumbersome process. If we are to stop the spread of this disease, it is imperative that assistance in contact tracing and notification becomes an important part of the testing and counseling arena.

\section{Conclusion}

It is important to note that the use of HIV testing and counseling can assist in the development of an interactive process to educate persons in the actions they must engage in to avoid exposure or further transmission of HIV. Failure on the part of health professionals to accomplish this task will have unheard of repercussions.

1. Friedland GH, Klein RS: Transmission of the human immunodeficiency virus. $N$ Engl $J$ Med 1987;317:1125-1134.

2. Fischl MA, Dickinson GM, Scott GM, et al: Evaluation of heterosexual partners, children, and household contacts of adults with AIDS. JAMA 1987;257:640-644.

3. Franzen C, Jerthborn M, Biberfield G: Four generations of heterosexual transmission of LAV/HTLV-III in a Swedish town. Read before the Second International Conference on AIDS, Paris, June 23-25, 1986.

4. Calabrese LH, Gopalakrishna KV: Transmission of HTLV-III infection from man to woman to man, letter. N Engl J Med 1986;314:987.

5. Schoenbaum EE, Selwyn PA, Feiner CA, et al: Prevalence and risk factors associated with HTLV-III/LAV antibodies among intravenous drug users in a methadone clinic in New York City. Read before the Second International Conference on AIDS, Paris, June 23-25, 1986.

6. Francis DP, Chin J: The prevention of acquired immunodeficiency syndrome in the United States. JAMA 1987;257:1357-1366.

7. Calabrese LH, Proffitt MR, Rehm S, et al: Lack of correlation between HTLV-III antibody and promiscuity in a low-incidence area. $N$ Engl $J$ Med 1985;312:1256-1257.

8. Goedert JJ: What is safe sex? Suggested standards linked to testing for human immunodeficiency virus. N Engl $J$ Med 1987;316:1339-1342. 9. Recommendations for prevention of HIV transmission in health care settings. MMWR 1987;36(suppl):1S-185S

10. Dardick L, Grady KE: Openness between gay persons and health professionals. Ann Intern Med 1980;93:115-119.

11. Public health service guidelines for counseling and antibody testing to prevent HIV infection and AIDS. MMWR 1987;36:509-525.

12. Bayer R, Levine C, Wolf SM: HIV antibody screening: An ethical framework for evaluating proposed programs. JAMA 1986;256:17681774

13. Henry K, Maki M, Crossley K: Analysis of the use of HIV antibody testing in a Minnesota hospital. JAMA 1988;259:229-232.

14. Marzuk PM, Tierney H, Tardiff $\mathrm{K}$, et al: Increased risk of suicide in persons with AIDS. JAMA 1988;259:1333-1337.

15. Johnson J: AIDS-related psychosocial issues for the patient and physician. JAOA 1988;88:234-238.

16. Ranki A, et al: Long latency precedes overt seroconversion in sexually transmitted human immunodeficiency virus infection. Lancet 1987;2:589-593

17. Hopkins DR: Public health measures for prevention and control of AIDS Pub Health Rep 1987;102:463-467.

18. Sherer R: Physician use of the HIV antibody test. JAMA 1988;259:264265.

19. Finebert HV: Education to prevent AIDS: Prospects and obstacles. Science 1988;239:592-596.

20. Ostrow DG (ed): Biobehavioral Control of AIDS. New York, Irvington Publishers, Inc, 1987.

21. Making Sex Safer, pamphlet. Rockville, Md, 1987, American College Health Association, 1987

22. Safe Sex: Charlottesville AIDS resource network, pamphlet. Rockville, Md, American College Health Association, 1986.

From the Department of Rheumatic and Immunologic Disease, Cleveland Clinic Foundation, Cleveland, Ohio.

For reprints, address Dr Calabrese, Cleveland Clinic Foundation, 9500 Euclid Ave, Cleveland OH 44195-5028. 